\title{
Els verbs psicològics pronominals catalans i l'alternança emotiva/volitiva
}

\section{Catalan Pronominal Psychological Verbs and Emotional/Volitional Alternation}

CARLES Royo [carlesroyo@ub.edu]

Universitat de Barcelona, Espanya

\section{RESUM}

Hi ha dos grups de verbs psicològics pronominals catalans que regeixen un sintagma preposicional (interessar-se \{per/en\}, penedir-se de) i que es diferencien dels verbs psicològics ergatius pronominals (emocionar-se, emmurriar-se). Les característiques semàntiques del subjecte experimentador d'aquests predicats són compatibles amb un pacient $\mathrm{i}$, alhora, amb un agent que actua com una causa interna iniciadora de la seva pròpia experiència psicològica. Proposo que participen en oracions amb una estructura inacusativa agentiva, amb un subjecte experimentador legitimat com a argument intern que ocupa la posició d'argument extern de forma derivada. Són oracions que expressen voluntarietat en l'experimentador $\mathrm{i}$ alguns d'aquests verbs presenten un alternant de caràcter emotiu que els permet participar en una alternança emotiva/volitiva.

\section{Paraules Clau}

Agent; alternança verbal; català; inacusativitat; pacient; verb pronominal; verb psicològic; voluntarietat

\section{Abstract}

There are two groups of Catalan pronominal psychological verbs that govern a prepositional phrase (interessar-se per/en 'take an interest in', penedir-se de 'regret') which differ from pronominal ergative psychological verbs (emocionar-se 'get excited', emmurriar-se 'get angry'). The semantic characteristics of the experiencer subject of these predicates are compatible with a patient and, at the same time, with an agent that acts as an internal cause initiating its own psychological experience. I propose they take part in sentences with an agentive unaccusative structure, with an experiencer subject licensed as an internal argument that occupies the position of an external argument in a derivative way. These sentences express willingness in the experiencer and some of the verbs have an emotional alternant that allows them to take part in an emotional/volitional alternation. 


\section{KeYWORDS}

Agent; verbal alternation; Catalan; unaccusativity; patient; pronominal verb; psychological verb; willingness

REBUT 2017-12-01; ACCEPTAT 2018-04-25

Aquest treball s'ha beneficiat d'un ajut del Ministerio de Economía y Competitividad a través del projecte de recerca FFI2014-56258-P. Agraeixo a Jaume Mateu i Jordi Ginebra els seus comentaris i suggeriments. Tots els possibles errors d’aquest article només són responsabilitat meva.

\section{Introducció}

Diversos verbs psicològics catalans presenten una morfologia pronominal amb el clític es/se i solen formar oracions amb un sintagma preposicional (SPrep): L'Enric s'emociona amb la música; L'Enric s'emmurria amb aquesta situació; L'Enric s'interessa \{en/per\} la literatura; L'Enric es penedeix del que ha fet. Una anàlisi d'aquestes quatre oracions mostra la diferència de comportament dels verbs que hi participen. Una primera diferència és que el SPrep de les dues primeres oracions és optatiu $(1 a-b)$ i, en canvi, el de les dues últimes és obligatori $(1 c-d) .{ }^{1}$

(1) a. L'Enric s'emociona (amb la música).

b. L'Enric s'emmurria (amb aquesta situació).

c. L'Enric s'interessa *(\{en/per $\}$ la literatura).

d. L'Enric es penedeix ${ }^{*}$ (del que ha fet).

Una altra diferència és que la primera oració i la tercera presenten un alternant no pronominal en oracions sense cap SPrep $(2 a / c)$, en contrast amb la segona i la quarta, que no tenen alternant no pronominal $(2 b / d) .^{2}$ Ara bé, encara que en els alternants no pronominals de $(2 a / c)$ hi participen verbs ObjExp de Pesetsky (1995) - verbs amb experimentador objecte- ${ }^{3}$ l'alternant no pronominal de $(2 a)$ conté un verb amb experimentador acusatiu o AcExp (ti-

1 En determinats contextos, és possible utilitzar el verb penedir-se sense un SPrep: «Quan l'altre s'ha penedit» (Torralba 2012: 139, títol); «¿I quan l'agressor s’ha penedit? ¿Podem, tal vegada, perdonar-lo?» (ibid., 147); «Penediu-vos, doncs, i convertiu-vos perquè siguin esborrats els vostres pecats» (La Bíblia, Ac 3,19). En aquests contextos el verb es comporta com els predicats ergatius pronominals no inherents o inherents (cf. $(1 a-b))$, que formen oracions en què es pot sobreentendre implícitament —en l'escena conceptual - la causa que provoca l'experiència psicològica, a través d'un SPrep prescindible caracteritzat com un adjunt lèxic (cf. Mateu 2000): ¿I quan l'agressor s'ha penedit (de l'agressió feta)? Rigau (1994: 33, nota 7) recull un refrany amb un ús no pronominal del verb: Val més tenir que penedir. Pel que fa al règim i la substitució pronominal del SPrep del verb interessar-se, vegeu Ginebra i Montserrat 2002: 47-48, nota 1.

2 Segons el DIEC2, i a diferència de emmurriar, el verb desemmurriar sí que té un alternant no pronominal transitiu. Segons el DCVB, emmurriar i el sinònim enfurrunyar són verbs transitius.

3 Les oracions angleses amb verbs ObjExp poden ser ambigües: agentives, causatives no agentives i estatives (cf. Arad 1998). 
pus II de Belletti i Rizzi 1988) i, en canvi, l'alternant no pronominal de (2c) presenta un verb amb experimentador datiu o DatExp (tipus III de Belletti i Rizzi 1988). ${ }^{4}$ A més, l’alternant no pronominal de $(2 c)$ presenta en català una duplicació de clític de forma obligatòria o gairebé obligatòria (cf. Laca 1986; Todolí 1998, 2008).
(2) a. L'Enric s'emociona amb la música.
$\rightarrow \quad$ La música emociona l'Enric.
b. L'Enric s'emmurria amb aquesta situació. $\rightarrow$
*Aquesta situació emmurria l'Enric.
c. L'Enric s'interessa $\{$ en / per $\}$ la literatura. $\rightarrow$
A l'Enric li interessa la literatura.
d. L'Enric es penedeix del que ha fet.
${ }^{\star}$ A l'Enric li penedeix el que ha fet.

L'alternança causativa recollida a $(2 a)$, entre una oració causativa de canvi d'estat amb un verb no pronominal i una oració incoativa amb un verb ergatiu pronominal, ha estat força descrita en els treballs de recerca lingüística (cf. Cabré i Mateu 1998; Rosselló 2008: §S 13.3.7.1; GIEC \$21.5b). Assumeixo la proposta estructural de Cuervo (2003: \$1.3.4$\$ 1.3 .5)$ per als dos alternants de $(2 a)$, tot i que l'autora no es refereix específicament als verbs psicològics. L'alternant causatiu presenta una estructura argumental esdevenimental transitiva bieventiva $\left(\mathrm{S} v_{\mathrm{DO}}+\mathrm{S} v_{\mathrm{BE}}\right)$ amb un experimentador objecte (cf. (31)), i l'alternant incoatiu o ergatiu, una estructura esdevenimental inacusativa bieventiva $\left(\mathrm{S} v_{\mathrm{GO}}+\mathrm{S} v_{\mathrm{BE}}\right)$ amb un experimentador subjecte intern i sense SPrep obligatori (cf. (30b)): seria la mateixa estructura de les oracions amb verbs ergatius pronominals inherents, com la de $(2 b)$, però sense alternant causatiu en aquest cas. $^{5}$

La similitud formal de les oracions de $(1 c-d)$ amb les dels verbs ergatius pronominals de ( $1 a$ b) —no inherents o inherents - podria fer pensar que són oracions amb la mateixa estructura argumental, ja tinguin alternants o no: una construcció inacusativa complexa amb un experimentador subjecte intern. Però hi ha diferències que les singularitzen: d'una banda, les oracions de $(1 c-d)$ presenten un SPrep obligatori que haurà de ser present en l'estructura argumental; de l'altra, l'alternança de (2c) —descrita per Rigau (1990) en el cas del verb agradar i per GIEC $\$ 21.5 a$ - és diferent de l’alternança causativa de $(2 a)$, perquè conté un alternant no pronominal que no és esdevenimental causatiu sinó estatiu, i que, segons Cuervo (2003, 2010a), presenta una estructura inacusativa simple estativa $\left(\mathrm{S} v_{\mathrm{BE}}\right)$ amb un subjecte intern i un experimentador datiu argument extern introduit per un aplicatiu alt. ${ }^{6}$

4 Participen també en l'alternança de (2c) els verbs DatExp agradar i desagradar (cf. DIEC2). Jané (1979) defensa que el diccionari normatiu hauria d'incloure l'alternant plaure's en del verb DatExp plaure, ja que el mateix diccionari l'accepta en uns quants exemples. Sobre la inclusió del verb català interessar dins el grup de predicats DatExp, vegeu Royo 2017a. Pel que fa al verb doldre, vegeu la nota 9.

5 Cuervo (2003) assumeix que els verbs es formen a la sintaxi per combinació d'una arrel lèxica i d'un nucli verbal $v$ (cf. Marantz 1997), amb tres tipus possibles de $v$ petites introductores d'events (cf. Harley 1995; Folli i Harley 2005): $v_{\mathrm{DO}}, v_{\mathrm{GO}}$ i $v_{\mathrm{BE}}$, cadascuna de les quals es corresponen amb tres tipus bàsics d'events (activitats, canvis i estats, respectivament). Lestructura bieventiva oracional és una configuració no prevista en marcs teòrics més restrictius (cf. Marantz 2013: 161). Per desfer possibles ambigüitats, utilitzo el terme event amb un sentit diferenciat del terme esdeveniment: els events inclouen tant els esdeveniments (actius o dinàmics) com els estats (estatius).

6 Per als datius introduïts per nuclis aplicatius, vegeu Baker (1988), Marantz (1993), Harley (1995), Pylkkänen (2008) i Anagnostopoulou (2003). 
A diferència de l'alternança causativa de $(2 a)$, en què el participant més prominent o protagonista de l'escena conceptual canvia en cada alternant (3), en l'alternança de (2c) - que anomeno alternança emotiva/volitiva - l'experimentador és el protagonista o participant més prominent en tots dos alternants (4); aquesta preeminència semàntica de l'experimentador es correspon amb la seva preeminència sintàctica en tots dos alternants de (4), en ocupar la posició inicial de l'oració en l'ordre oracional no marcat, posició prototípica del subjecte (cf. Royo 2017a: 67-69). A (4) l'alternant DatExp seria l'emotiu (4a) i l'altre alternant seria el volitiu (en realitat, (4b) seria emotiu i volitiu alhora), com veurem més endavant. ${ }^{7}$ A l'apartat següent estudio si a aquestes diferències se n'hi poden afegir d'altres que ens ajudin a esbrinar si l'experimentador subjecte de $(1 c-d)$ té o no té el mateix comportament sintàctic i semàntic que l'experimentador subjecte de $(1 a-b)$.

\section{(3) Alternança causativa}

a. La música \{emociona / commou / atabala $\underline{\text { l’Enric. }}$

b. L'Enric \{s'emociona / es commou / s'atabala\}.

(4) Alternança emotiva/volitiva

a. A l'Enric li \{interessa la literatura / agrada passejar amb la Maria / desagrada la feina\}.

b. L'Enric \{s'interessa per la literatura / s'agrada de passejar amb la Maria / es desagrada de la feina\}.

A continuació aplico una abreviació diferent a cadascun dels quatre tipus de verbs psicològics pronominals de (1), per tenir una etiqueta que els identifiqui i els diferenciï dels altres tres grups verbals en què tradicionalment s'han dividit els verbs psicològics (cf. Belletti i Rizzi 1988, i la llista recollida a l'annex final). Adjudico l'etiqueta Subj(i)Exp(pr) al grup de verbs com emocionar-se: verbs ergatius pronominals (pr) amb un subjecte intern (i) experimentador. Assigno l'etiqueta $\operatorname{Subj}(\mathrm{i}) \operatorname{Exp}(\mathrm{pr}-\mathrm{ci}$ ) —on $c i$ indica 'causa interna' - al grup de verbs ergatius pronominals inherents com emmurriar-se. ${ }^{8}$ Els grups de verbs com interessarse (en/per) i com penedir-se (de) els etiqueto, respectivament, SubjExp(pr-prep) i SubjExp(pr-prep) ${ }_{\mathrm{B}}$ : verbs pronominals (pr) amb un argument nominatiu experimentador - en una posició estructural per definir - que regeixen un argument preposicional obligatori (prep); el subín$\operatorname{dex}\left[{ }_{\mathrm{A}}\right]$ l'aplico als predicats que presenten un alternant amb datiu experimentador (DatExp) i el subíndex $\left[_{B}\right]$ als que no en tenen, tot i que alguns poden tenir altres alternants.

Dedicaré aquest treball a l'estudi d'aquests dos últims grups de verbs, els SubjExp(pr-prep) - agradar-se de, desagradar-se de, interessar-se \{en/per $\}$, plaure's en-i SubjExp(pr-prep) $)_{\mathrm{B}}$ - acular-se a, apiadar-se de, avenir-se amb, embeure's \{en/de\}, entossudir-se en (sinònim de encabotar-se en, entestar-se en i obstinar-se en), penedir-se de, etc. A més, descric un tipus d'alternança, que

7 Per a una explicació sobre la recategorització dels casos i dels papers temàtics en tots dos alternants amb el verb agradar, vegeu Rigau (1990: 13; 1994; 33-34).

8 Els verbs ergatius pronominals - no inherents o inherents - denoten un esdeveniment que es pot concebre com a causat internament. Amb l'etiqueta $\operatorname{Subj}(\mathrm{i}) \operatorname{Exp}(\mathrm{pr}-\mathrm{ci})$ vull indicar que els verbs ergatius pronominals inherents només poden tenir una causa interna, ja que, a diferència dels no inherents, l'esdeveniment no es pot iniciar per una força inanimada en un alternant AcExp (cf. Masullo 1999; Rosselló 2008; Abrines 2016). 
anomeno alternança emotiva/volitiva, en la qual participen els verbs SubjExp(pr-prep) ${ }_{\mathrm{A}}$ amb alternants emotius DatExp i determinats verbs SubjExp(pr-prep) $)_{\mathrm{B}}$ amb altres alternants emotius. ${ }^{9}$

Per fer la descripció de l'estructura argumental de les oracions amb aquests predicats, utilitzaré el marc teòric establert per Cuervo (2003: \$1). Des d’un enfocament neoconstruccionista, l'autora desenvolupa una teoria de l'estructura argumental amb tres tipus de nuclis: els introductors d'events ( $v$ petita), els introductors d'arguments (Veu i aplicatius) i les arrels. ${ }^{10}$

\section{Els verbs SubjExp(pr-prep $)_{A}$ i SubjExp(pr-prep $)_{B}$}

Els verbs SubjExp(pr-prep) $)_{A}$ i SubjExp(pr-prep) $)_{B}$ 'assemblen als predicats ergatius pronominals —Subj(i)Exp(pr) i Subj(i)Exp(pr-ci)—:"11 la construcció amb el clític es/se els dona una aparença equiparable, admeten o exigeixen un SPrep en les oracions en què participen (1) i la construcció sovint pot expressar una semàntica incoativa, d'inici d'un event. A més, els Subj(i)Exp(pr-ci) no tenen alternants sintàctics AcExp i els SubjExp(pr-prep) $)_{B}$ no en tenen de DatExp, fet que pot donar-los més similitud, ${ }^{12}$ encara que determinats verbs de totes dues classes poden tenir alternants

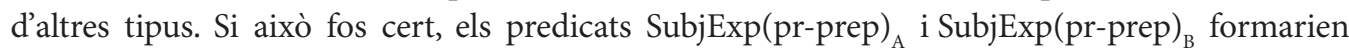

9 El terme alternança emotiva/volitiva inclou altres alternances diferents de la que s'estableix entre un alternant emotiu DatExp i un alternant volitiu SubjExp(pr-prep). L'alternant volitiu pot estar representat per un predicat SubjExp(pr-prep), amb un alternant emotiu que no és DatExp. Per exemple, tot i que el verb doldre participa en aquesta alternança, no considero que l'accepció pronominal del verb (doldre's de: La Maria es dol del que has fet) sigui un predicat SubjExp(pr-prep) $)_{\mathrm{A}}$, sinó un predicat SubjExp(pr-prep) $)_{\mathrm{B}}$, ni que l'alternant no pronominal del verb sigui l'accepció DatExp de doldre ('recar, saber greu'), sinó una altra (A la Maria li dol el que has fet). O un verb com avergonyir pot presentar una alternança emotiva/volitiva entre dos alternants pronominals: un d'emotiu Subj(i)Exp(pr) (avergonyir-se:

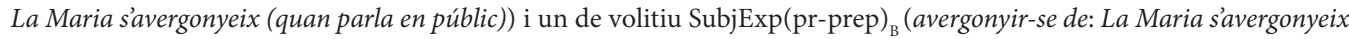
del que ha fet). Com que és un aspecte de l'alternança que va més enllà de l'objectiu d'aquest article, em remeto a Royo $2017 b$.

10 Per als introductors d'events i per als nuclis aplicatius introductors d'arguments datius, vegeu la nota $5 \mathrm{i}$ la nota 6, respectivament. Pel que fa al nucli SVeu introductor de l'argument extern, vegeu Kratzer (1996) i Alexiadou et al. (2006). D'altra banda, basant-se en Levin (1999), Cuervo accepta que hi poden haver arguments que siguin complement de l'arrel (cf. Harley 2014; Cuervo 2014); és un tema de debat i altres autors usen estructures en què les arrels no duen complements (cf. Alexiadou 2014; Acedo-Matellán i Mateu 2015).

11 Gràcia (1989: 33) anomena pronominals purs els verbs pronominals que no tenen alternants causatius, amb exemples que inclouen el verb SubjExp(pr-prep) ${ }_{\mathrm{B}}$ penedir-se i d'altres com abstenir-se, suïcidar-se: En Pau se n’ha penedit, La Maria s'ha abstingut, Primo Levi es va sü̈cidar (Gràcia 1989: 33 (8)). Tot i que afirma expressament que no vol estudiar aquesta qüestió, assenyala que «El fet que ara nosaltres els distingim dels ergatius no vol dir que necessàriament hagin de rebre una anàlisi diversa».

12 Marín (2015: 13) dona una llista de verbs de l'espanyol que considera no alternants dels AcExp, sense més distinció dins el grup: arrepentirse, atreverse, embotarse, empecinarse, empeñarse, encapricharse, encariñarse, equivocarse, escamarse, obstinarse, resignarse, vanagloriarse. En català, a diferència de l'espanyol, l'exigència dels clítics $h i$ i en en les oracions sense un SPrep explícit fa transparent la distinció entre els verbs Subj(i)Exp(pr-ci) — sense clític - i els verbs SubjExp(pr-prep $)_{\mathrm{B}}$ —amb clític —, fet que pot ajudar a distingir quins predicats catalans corresponents a aquesta llista són Subj(i)Exp(pr-ci) —com encarcarar-se 'embotarse' o escamnar-se 'escamarse' - i quins són SubjExp(pr-prep) B $_{\mathrm{B}}$ determinats contextos — com penedir-se 'arrepentirse' o obstinar-se/entestar-se 'empecinarse'-, a banda d'altres consideracions que es puguin fer sobre algun verb concret de la llista. La GIEC ( $\$ 21.5 b)$ equipara els verbs obstinar-se, entossudir-se, entestar-se, delir-se, desviure's, frisar(-se) als verbs ergatius pronominals inherents com desmaiar-se, pel seu comportament incoatiu i per no tenir alternants transitius. 
oracions inacusatives bieventives amb un subjecte argument intern com les dels predicats Subj(i) $\operatorname{Exp}(\mathrm{pr})$ i Subj(i)Exp(pr-ci), segons la proposta estructural de Cuervo (2003: \$1.3.5) per a les oracions amb verbs ergatius pronominals.

Ara bé, una anàlisi d'aquests predicats permet diferenciar-los dels ergatius pronominals. A més de la presència obligatòria del SPrep a l'oració, a continuació veurem que els verbs SubjExp(pr-prep) ${ }_{\mathrm{A}}$ (especialment interessar-se $\left.\{e n / p e r\}\right)$ i SubjExp(pr-prep $)_{\mathrm{B}}$ (penedir-se de) presenten un tret semàntic de voluntarietat o agentivitat que els diferencia dels Subj(i) $\operatorname{Exp}(\mathrm{pr})$ (emocionar-se) i Subj(i)Exp(pr-ci) (emmurriar-se). Partint d'aquest supòsit inicial, a continuació aprofundiré en els aspectes semàntics i sintàctics dels verbs SubjExp(pr-prep) i SubjExp(prprep) $)_{\mathrm{B}}$ per deduir quina estructura argumental presenten i diferenciar-la, a través de la comparació, de l'estructura dels verbs $\operatorname{Subj}(\mathrm{i}) \operatorname{Exp}(\mathrm{pr})$ i Subj(i) $\operatorname{Exp}(\mathrm{pr}-\mathrm{ci})$.

\subsection{Arguments a favor d'una natura oracional agentiva dels predicats SubjExp(pr-prep $)_{A}$ i SubjExp(pr-prep $)_{B}$}

La majoria d'oracions amb verbs SubjExp(pr-prep) ${ }_{B}$ denoten un subjecte experimentador amb una funció molt similar a un agent, que pot intervenir amb voluntarietat en la predicació verbal (5).

(5) Verbs SubjExp(pr-prep)

a. L'Enric es va \{apiadar / compadir\} \{voluntàriament / 'sense adonar-se'n\} del seu pare.

b. L'Enric s'avé \{volgudament / *sense adonar-se’n\} amb la Maria.

c. L'Enric es va embeure \{conscientment / 'sense adonar-se'n\} en la redacció del document.

d. L’Enric es va \{encabotar / entestar / entossudir / obstinar $\}$ intencionadament / 'sense adonar-se'n\} a portar-li la contrària.

e. L'Enric es va penedir \{voluntàriament / *sense adonar-se'n $\}$ d'haver-ho fet.

Als exemples de (5) s'hi mostra la facilitat dels verbs SubjExp(pr-prep) в $_{\text {p }}$ er denotar l'acció voluntària d'un subjecte experimentador i la dificultat per denotar una acció involuntària. Amb els verbs Subj(i)Exp(pr) (6) i Subj(i)Exp(pr-ci) (7), en canvi, hi ha facilitat per denotar una acció involuntària, tot i que alguns verbs no descarten tampoc una certa voluntarietat.

(6) Verbs Subj(i)Exp(pr)

a. L'Enric s'emociona $\left\{{ }^{*}\right.$ intencionadament / sense adonar-se’n $\}$ amb la música.

b. L'Enric s' $\{$ espanta/esparvera $\}$ \{*intencionadament / sense voler $\}$ amb la tempesta.

c. L'Enric es commou \{*intencionadament / sense adonar-se'n\} amb les teves paraules.

d. L'Enric es desanima \{'intencionadament / sense adonar-se’n $\}$ amb aquesta situació. 
(7) Verbs Subj(i)Exp(pr-ci)

a. L'Enric s'abstreu \{'intencionadament / sense adonar-se'n $\}$ amb pensaments imaginaris.

b. L'Enric es va \{emmurriar/enfurrunyar $\}\{$ expressament / sense adonar-se'n $\}$ amb l'actitud del seu pare.

c. L'Enric es va ensonyar $\left\{{ }^{*}\right.$ conscientment / sense adonar-se'n $\}$ amb tantes il-lusions.

d. L'Enric es va tocar $\left\{{ }^{*}\right.$ intencionadament / sense adonar-se'n $\}$ amb tantes preocupacions.

El contrast entre (5) i (6)-(7) amb adverbis de voluntarietat redundants no és una prova clara, però pot obrir un debat a l'hora d'establir i diferenciar l'estructura argumental i eventiva dels dos grups de predicats ergatius pronominals $(1 a-b)$, d'una banda, i la dels altres dos grups $(1 c-d)$, de l'altra. L'agentivitat i la voluntarietat són dos paràmetres semàntics que solen estar estretament relacionats (cf. Hopper i Thompson 1980, Tsunoda 1985) i no necessàriament vinculats a una estructura oracional transitiva (cf. Tsunoda 1985, en contra de Hopper i Thompson 1980).

La similitud del subjecte dels verbs SubjExp(pr-prep) ${ }_{\mathrm{B}}$ amb un agent pot ser una dada a favor de la posició estructural d'aquest subjecte com un argument extern, a diferència del subjecte argument intern dels verbs $\operatorname{Subj}(\mathrm{i}) \operatorname{Exp}(\mathrm{pr})$ i Subj(i)Exp(pr-ci). No és una diferència nítida i pot ser discutible, ja que no es pot descartar la voluntarietat en tots els verbs ergatius pronominals: probablement hi fa falta un estudi aprofundit de la noció de causa interna, especialment quan l'argument causa interna és un experimentador humà (amb voluntat) que fa la funció gramatical de subjecte i sigui l'única causa present a l'oració.

Pel que fa als verbs SubjExp(pr-prep) agradar-se de, desagradar-se de i plaure's en, estan en força desús en diversos dialectes catalans; en canvi, el verb interessar-se \{en/per\} hi és ben viu. ${ }^{13}$ És probable que el model semàntic i sintàctic dels verbs SubjExp(pr-prep) ${ }_{\mathrm{B}}$ caracteritzi igualment els alternants SubjExp(pr-prep) de l'alternança emotiva/volitiva: per aquest motiu, acabarien prevalent en l'ús dels parlants els verbs que més fàcilment puguin denotar un subjecte experimentador pròxim a un agent que actua amb voluntarietat —com interessar-se $\{\mathrm{en} / \mathrm{per}\}$ (8) - , a diferència dels que presenten més dificultat per denotar-lo en prioritzar la semàntica emocional (com agradar-se de, desagradar-se de, plaure's en), encara que la voluntarietat no s'hi pugui descartar del tot.

(8) L'Enric s'interessa \{intencionadament / *sense adonar-se’n $\{$ en/per $\}$ la literatura.

He trobat uns quants exemples d'ús del verb agradar-se de que es poden concebre, per la semàntica oracional, com una acció voluntària d’un agent (9). ${ }^{14}$ És una apreciació intuïtiva que

13 Rigau (1990: 10-11) assenyala que en el parlar del bisbat de Girona es poden trobar construccions del verb agradar amb aquesta alternança: Al rei li ha agradat la pastoreta, El rei s'ha agradat de la pastoreta. Com interessar-de \{en/per\}, el verb doldre’s de també es manté força viu, però no el considero un verb SubjExp(pr-prep) (vegeu la nota 9).

Actualment alguns parlants de l'espanyol poden utilitzar gustarse de en un registre col-loquial: Esa chica se gusta de mi (Rodríguez 2015: 238); María no se gusta de mi (Maldonado 2008: 192).

14 Diversos autors assenyalen que el verb gustar de l'espanyol ha sofert una reanàlisi com un mecanisme de desagentivització, en què la configuració original NOM+GUSTAR expressava voluntarietat en l'experimentador (María gusta de la música) i, en canvi, l'actual DAT+GUSTAR expressa involuntarietat (A María le gusta la música): cf. Batllori 2012; Elizaincín i González 2016. Els exemples de gustar que aquests autors aporten de l'espanyol antic són sense el clític se i amb un objecte que pot ser directe o preposicional, però Batllori (2012) també recull exemples del verb agradar de l'espanyol en oracions amb objecte preposicional i amb el clític se. 
caldria confirmar amb parlants que utilitzin habitualment aquest verb. De fet, el verb interessarse $\{$ en/per) participa amb facilitat en una oració d'imperatiu, cosa més dubtosa en la resta de verbs SubjExp(pr-prep) ${ }_{\mathrm{A}}$ (cf. la nota 17).

(9) a. [...] Però els homes de teatre són tossuts i śagraden de navegar a contracorrent. (Rostand 1985, al pròleg de Xavier Bru de Sala)

b. Guardeu-vos dels escribes, que es complauen a passejar-se amb llargues vestidures, i śagraden de les salutacions a les places, dels primers seients a les sinagogues i dels primers llocs als convits. (La Bíblia, Lc 20,46)

c. Qui cerca caragols o s'agrada de menjar-ne. (DCVB: veu caragoler (o cargoler) -era); Que cerca caragols o se n'agrada molt (or.). (DCVB, definició de caragolaire (o cargolaire))

d. La meva tia era piadosa i s'agradava de filosofar sobre matèries metafísiques. (Medina 1987: 77)

e. Era d'aspecte distingit, però de caràcter desagradable i grosser, i śagradava de la cacera amb una passió extraordinària. (Liberal: 2012: 149-150)

Hi ha alguns verbs com alegrar-se o avergonyir-se que, tot i ser alternants intransitius de l'alternança causativa (10a), es resisteixen a prescindir del SPrep en determinats contextos (10b). ${ }^{15}$ Són verbs que poden presentar-se en contextos voluntaris amb un SPrep obligatori (11). Seguint el raonament fet en els paràgrafs anteriors, suggereixo que en la mesura que el verb alegrar-se (i avergonyir-se) denoti un subjecte experimentador amb més voluntarietat, exigirà el SPrep i es comportarà com un verb SubjExp(pr-prep) ${ }_{\mathrm{B}}(12 a)$; d'altra banda, en la mesura que accepti un subjecte menys voluntari, tendirà a no exigir el SPrep i a comportar-se com un verb Subj(i)Exp(pr), un alternant possible d'un verb AcExp (alegrar 'causar alegria (a algú)') (12b). A (12) tindríem dos alternants pronominals d'un subtipus d'alternança emotiva/volitiva (pronominal): L'Enric s'alegra vs. L'Enric se n'alegra. ${ }^{16}$

(10) a. La Maria \{alegra/avergonyeix l'Enric. $\rightarrow$ L'Enric s'\{alegra/avergonyeix\}. [alternança causativa]

b. M’\{alegro/avergonyeixo $\}$ de veure la teva actitud. $\rightarrow \mathrm{Me}^{*}\left(\mathrm{n}^{\prime}\right)$ \{alegro/avergonyeixo\}.

(11) a. Ja ho he fet, i no sé si alegrar-me’n o avergonyir-me’n.

b. Me n'alegro sincerament, de la teva decisió.

15 Belletti i Rizzi (1988: 348) preveuen que puguin existir dos grups de verbs psicològics que seleccionin cas genitiu per al tema, i posen com a exemples els verbs importare 'importar' i gioire 'alegrar-se': A me importa solo di questo; Gianni gioisce di questo (Belletti i Rizzi 1988: 348 (123) i (124)). Cf. llatí: Me $_{\mathrm{AC}}$ pudet tui ${ }_{\mathrm{GEN}}$, lit. M’avergonyeix de tu, i.e. 'm'avergonyeixo de tu'; $\mathrm{Me}_{\mathrm{AC}}$ paenitet tui ${ }_{\mathrm{GEN}}$, lit. Em compadeix de tu, i.e. 'em compadeixo de tu' (agraeixo a Jaume Mateu aquests exemples del llatí).

16 A la nota 9 hi ha una explicació breu sobre les diferents plasmacions de l'alternança emotiva/volitiva. Per a una discussió sobre les objeccions possibles al fet de relacionar la voluntarietat d'aquests verbs amb la presència del SPrep, vegeu Royo 2017b: \$2.2.5. Per a l’existència d’una accepció Subj(i)Exp(pr) dels verbs avergonyir i alegrar (cf. la segona oració de $10 a$ i 12b), vegeu l'exemple de l'accepció pronominal de avergonyir al DUVC S’avergonyeixen quan els fan parlar davant de tothom, i l'accepció pronominal de alegrar al GD62 'cessar d'estar trist, irat o massa seriós', amb l'exemple No s'alegra fàcilment. 
(12) a. L'Enric s'alegra del que has fet. $\rightarrow$ L'Enric se n'alegra. [SubjExp(pr-prep) $)_{B}$ ]

b. El que has fet alegra l'Enric. [alternant AcExp] $\rightarrow$ L'Enric s'alegra. [alternant Subj(i) $\operatorname{Exp}(\mathrm{pr})]$

Hi ha més dades que suggereixen que el subjecte experimentador d'oracions amb verbs SubjExp(pr-prep $)_{A}$ i SubjExp(pr-prep) $)_{B}$ presenta una funció molt similar a un agent, que pot intervenir amb voluntarietat en la predicació verbal, com la possibilitat d'admetre una clàusula de finalitat (13) o de formar oracions d'imperatiu (14). ${ }^{17}$

(13) a. L'Enric es va interessar en la literatura \{per / per tal de\} millorar la seva formació cultural.

b. 'L'Enric es va penedir d'haver-ho fet perquè el perdonessis.

c. L'Enric es va embeure en la redacció del document amb la intenció d'enllestir-lo com més aviat millor.

d. L'Enric s'avé amb la Maria per no sentir-se tan sol.

e. L'Enric es va \{encabotar / entestar / entossudir / obstinar $\}$ a portar-li la contrària amb la intenció de convèncer-la.

(14) a. Interessa't una mica pel que et dic!

b. Penedeix-te del que has fet!

La caracterització del subjecte com un participant oracional que actua de forma voluntària també és coherent amb la possibilitat que aquestes oracions tinguin una interpretació deòntica o radical amb determinades perífrasis verbals de modalitat (cf. Picallo 1990; Hengeveld i Mackenzie 2008: 176; Quer 2008: $\$ S ~ 25.1 .2$ ), que pressuposen el control humà (cf. Gavarró i Laca 2008: $\$ S ~ 23.4 .1)$ i en les quals «la perífrasi s'orienta cap a un agent, generalment el subjecte» (GIEC \$24.8.4.1). Les perífrasis modals haver de + infinitiu o poder + infinitiu poden tenir una interpretació deòntica i una altra d'epistèmica, segons el context en què apareguin. Aquí convé assenyalar la capacitat d'aquests predicats de tenir la interpretació deòntica. Uns quants exemples d'ús mostren aquesta possibilitat, segons algunes de les proves que ajuden a distingir totes dues interpretacions (cf. Picallo 1990, Gavarró i Laca 2008: \$S 23.4.3-4): les perífrasis modals d'interpretació deòntica poden aparèixer en construccions no temporals (15), en un ordre seqüencial de dos modals com haver de + poder (16), a més de la interpretació deòntica després de l'auxiliar haver (17).

17 El verb interessar-se \{en/per $\}$ (13a) accepta amb més facilitat una oració d'imperatiu o una clàusula de finalitat que la resta de verbs SubjExp(pr-prep) (agradar-se de, desagradar-se de, plaure’s en), en què totes dues proves són dubtoses: ?"Agrada't de la Maria!; ?'L’Enric es va agradar de la Maria \{amb la intenció de... / per (tal de)... / perquè + subjuntiu...\}. Més endavant comentaré aquest comportament. 
(15) a. [...] es basa en el contacte directe i l'experimentació com a eines per poder interessar-se en l'antropologia. (Ara: 25 de setembre del 2015) ${ }^{18}$

b. L'àvia Cinta sempre deia que s'han de rumiar bé les coses abans de fer-les perquè haver de penedir-se'n fa ser burro. (Blanco 2015: 7)

(16) És a dir, ha de donar la idea que els científics ajuden a generar coneixement i que quan aquest esdevé d'interès social [...] el visitant ha de poder interessar-s'hi. ${ }^{19}$

(17) a. El conjunt del Montsià n'ha estat un dels que ha sonat que ha pogut interessar-se per Cuéllar, exjugador del Nàstic. (Diari Més Ebre, 12 de novembre del 2010, p. 10)

b. [...] s'ha vist davant la imperiosa necessitat de buscar el port més pròxim i fins i tot ha pogut penedir-se d'haver comprat el vaixell. (Heinemann 2001: 19)

A més, els verbs SubjExp(pr-prep) i SubjExp(pr-prep) $)_{\mathrm{B}}$ poden formar oracions no estatives, ja que superen el test d'activitat amb l'adverbi durant i l'oració progressiva de gerundi (18). A diferència del que passava amb l'acceptació d'una clàusula de finalitat — cf. la nota 17—, tant el verb interessar-se $\{$ en/per $\}$ (18a) com la resta de verbs SubjExp(pr-prep) $)_{\mathrm{A}}$ (19) poden formar aquestes oracions.

(18) a. L'Enric \{es va interessar \{en/per\} la literatura durant una estona / s'està interessant \{en/ per\} la literatura\}.

b. L'Enric \{es va penedir durant uns instants d'haver-ho fet / s'està penedint d'haver-ho fet\}.

(19) a. L'Enric \{es va agradar de la Maria durant una estona / s'està agradant de la Maria\}.

b. L'Enric \{es va desagradar de la Maria durant una estona / s'està desagradant de la Maria\}.

Totes les proves d'aquest apartat $\$ 2.1$ menen a deduir que els verbs SubjExp(pr-prep) i SubjExp(pr-prep) ${ }_{\mathrm{B}}$ es construeixen amb un nucli funcional eventiu que no és un $\mathrm{S} v_{\mathrm{BE}}$, per tractar-se d'oracions que no són estatives. Si considerem que el model estructural dels verbs SubjExp(pr-prep) ${ }_{B}$ atrauria el dels verbs SubjExp(pr-prep), quina explicació pot rebre llavors que uns quants verbs SubjExp(pr-prep) «es resisteixin» a la interpretació agentiva i potser esdevenimental en alguna prova (cf. la nota 18$)$ ?

L'explicació pot consistir en el fet que l'alternança emotiva/volitiva s'esdevé amb verbs emotius en els alternants DatExp —el que Arad (1998) anomena oracions pròpiament «psych», bàsicament estatives—, que se situen al límit entre l’emoció i la volició en l’alternant SubjExp(pr-prep) - però més clarament volitius en el cas dels verbs SubjExp(pr-prep) $)_{\mathrm{B}}$-: el nom d'alternança emotiva/volitiva recull aquesta última observació. Els verbs SubjExp(pr-prep) ${ }_{\mathrm{A}}$ de semàntica més íntimament emotiva -com agradar-se de, desagradar-se de o plaurés en- són els que mostren més resistència a la interpretació agentiva, tot i que oracions com les de (9) poden suggerir que tampoc és una interpretació impossible. La possibilitat d’acceptar un agent es facilita per

18 <http://www.ara.cat/premium/Museu-Etnologic-Barcelona-reobre-portes_0_1438056225.html> (consulta: juliol del 2016).

19 <http://openaccess.uoc.edu/webapps/o2/bitstream/10609/1131/2/27467tfc.pdf.txt> (consulta: juliol del 2016). 
una semàntica més puntual de la predicació verbal, com 'obtenir grat' (agradar-se de), 'treure desgrat' (desagradar-se de), 'mostrar interès' (interessar-se \{en/per\}) o 'treure plaer' (plaure’s en), més que no pas un grat, desgrat, interès o plaer més estable i mantingut, característica semàntica de les oracions amb els alternants DatExp (agradar, desagradar, interessar, plaure).

Amb els tests d'activitat dels verbs SubjExp(pr-prep $)_{\mathrm{A}}$ - $(18 a)$ i (19) - es veu que la semàntica de les oracions amb l'adverbi durant indica que l'interès, el grat, el desgrat o el plaer és momentani o d'un temps determinat, molt allunyat del valor més estable i durador d'aquests verbs quan no són pronominals (verbs DatExp). Loració progressiva de gerundi indica el caràcter incoatiu dels predicats SubjExp(pr-prep) ${ }_{\mathrm{A}}$, d'acció encara no acomplida. Potser aquesta possibilitat de denotació puntual és la que permet que verbs amb un subjecte experimentador (SubjExp) com enyorar o compadir puguin formar els verbs enyorar-se (de) o compadir-se (de), per passar de denotar un enyor o una compassió habitual (enyorar, compadir) a un enyor o una compassió puntual (enyorar-se de, compadir-se de).

Tenint en compte totes aquestes dades, es pot establir una hipòtesi de partida a l'hora d'estudiar l'estructura argumental dels verbs SubjExp(pr-prep) ${ }_{A}$ i SubjExp(pr-prep) $)_{B}$. Si els verbs $\operatorname{Subj}(\mathrm{i}) \operatorname{Exp}(\mathrm{pr})$ i Subj(i)Exp(pr-ci) es poden caracteritzar com a predicats que participen en oracions inacusatives amb un subjecte experimentador argument intern pacient - seguint la proposta de Cuervo (2003: \$1.3.5) per a les oracions incoatives_, compatible amb la caracterització semàntica emotiva d'aquests predicats i la facilitat que tenen per expressar una acció involuntària (6)-(7), la caracterització semàntica d'un subjecte experimentador que actua amb voluntarietat en oracions de predicats $\operatorname{SubjExp}(\text { pr-prep })_{\mathrm{A}}$ i SubjExp(pr-prep) ${ }_{\mathrm{B}}$ pot ser compatible amb una estructura argumental amb un subjecte experimentador agent que sigui argument extern. Segons aquesta hipòtesi de partida, tindríem un contrast entre (20a) i (20b), amb una representació força esquemàtica de l'estructura argumental, amb un subjecte experimentador dins el $\mathrm{S} v$ a $(20 a)$ i un subjecte experimentador fora del S $v$ a (20b).

(20) a. Subj(i) $\operatorname{Exp}(\mathrm{pr})$ : emocionar-se [emotiu amb alternant AcExp] Subj(i)Exp(pr-ci): emmurriar-se [emotiu sense alternant AcExp] b. SubjExp(pr-prep) $)_{\AA}$ interessar-se $\{$ en/per $\}$ [volitiu amb alternant DatExp] SubjExp(pr-prep) $)_{\mathrm{B}}$ : penedir-se de [volitiu sense alternant DatExp]

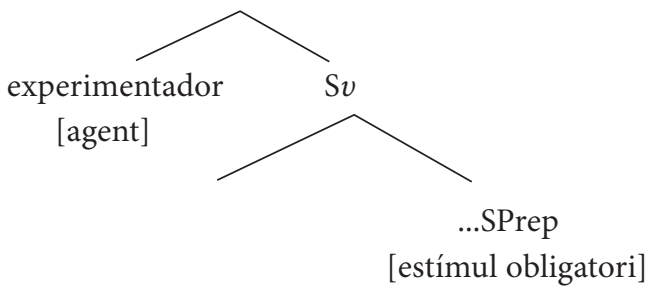

[hipòtesi per comprovar] 


\subsection{Arguments en contra d'una natura oracional agentiva}

Un cop establerta aquesta hipòtesi d'estudi, hi ha uns quants arguments que la contradiuen. Rigau (1994) estudia els verbs pronominals del català. Afirma que en aquestes oracions el clític absorbeix el paper temàtic de benefactiu i, aleshores, «la presència d'un argument intern tema és necessària per a la legitimació d'un complement de V' com és el complement benefactiu» (Rigau 1994: 38): un benefactiu no pot aparèixer mai amb verbs intransitius o utilitzats intransitivament $\left({ }^{\star}\right.$ En Pere no es beu). Arriba a la conclusió que els verbs pronominals o són transitius ${ }^{20}$ o són inacusatius. D’una banda, els verbs SubjExp(pr-prep) ${ }_{A}$ i SubjExp(pr-prep) ${ }_{B}$ participen en oracions que no són transitives $i$, de l'altra, en un plantejament clàssic de la inacusativitat el subjecte oracional no pot ser un argument extern, cosa que invalidaria la hipòtesi de partida d’un subjecte experimentador argument extern. A l’apartat següent $\$ 3$ reprendré aquesta última afirmació per matisar-la.

Basant-se en la divisió en dos grups verbals de Demonte (1989), Gallego (2010) estudia els predicats de règim verbal de l'espanyol. Arriba a la conclusió que aquests predicats o són inergatius o són inacusatius estatius. Segons Gallego, en els inergatius hi ha un subjecte agentiu i presenten un SPrep prescindible caracteritzat com un adjunt lèxic (cf. Mateu 2000); en canvi, els inacusatius estatius formen oracions estatives amb un subjecte no agentiu i amb un SPrep imprescindible, que és el predicat d’una predicació seleccionada per l’arrel. Ara bé, els exemples que Gallego (2010: 253 (57)) utilitza amb diferents verbs són vàlids per a l'espanyol, però en català l'existència dels clítics hi i en mostren de forma transparent quan és obligatori el SPrep. Entre altres verbs, Gallego (2010: 253) fa referència al verb empeñarse (en) 'entestar-se (en)',

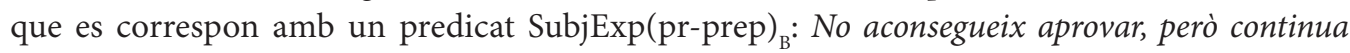
entestant-s'hi (exemple de Gallego de l'espanyol: No consigue aprobar, pero continua empeñándose). Segons aquest postulat, si acceptem la hipòtesi agentiva amb un subjecte argument extern dels verbs SubjExp(pr-prep) $)_{A}$ i SubjExp(pr-prep) $)_{B}$, caldria afirmar que són inergatius, amb un subjecte extern; però el fet de tenir un SPrep obligatori menaria a afirmar que són inacusatius estatius, amb un subjecte intern. Per tant, queda per resoldre la caracterització sintàctica de les oracions en què participen aquests predicats. ${ }^{21}$

Un tercer argument que contradiu la hipòtesi agentiva és que el subjecte experimentador de les oracions amb verbs SubjExp(pr-prep) i SubjExp(pr-prep) es pot concebre com un pacient que expressa un estat resultant. Són predicats que poden participar en construccions resultatives (21), caracterització compatible amb un subjecte intern pacient d'una construcció inacusativa. En aquest punt es comporten com els verbs ergatius pronominals (22).

20 Armstrong (2016) explica les oracions pronominals transitives de l'espanyol —com zampar-se algo- amb una preposició nul-la defectiva $\mathrm{P}_{[\phi]}$ incorporada al verb. Dona uns quants exemples d'oracions amb un significat psicològic metafòric: beber-se la fortuna, comer-se un gol, comer-se una reunión, fumar-se/mamar-se la quincena, patinar-se todo el dinero.

21 Armstrong (2016) qualifica d'inergatius un grup de verbs pronominals de l'espanyol etiquetats per Masullo (1992) com a predicats antipassius: aprovecharse (de), compadecerse (de), deshacerse (de), despedirse (de), desquitarse (de), ensañarse (con), incautarse (de), jactarse (de), olvidarse (de), quejarse (de), vanagloriarse (de). L'autor reconeix que és un grup verbal força heterogeni; aquesta heterogeneïtat es fa evident en comprovar que el corresponent verb català compadir-se (de) és un verb psicològic que permet una construcció d'estat resultant — cf. l'exemple de (27b) — i es pot incloure dins el grup de predicats SubjExp(pr-prep) ${ }_{\mathrm{B}}$, a diferència d'altres predicats esmentats per l'autor. 
(21) a. L'Enric s'interessa $\{$ en / per $\}$ la literatura. $\rightarrow$ L'Enric $\{$ està / ha quedat $\}$ interessat $\{$ en / per\} la literatura. [SubjExp(pr-prep) ${ }_{A}$ ]

b. L'Enric es penedeix del que ha fet. $\rightarrow$ L'Enric \{està / ha quedat $\}$ penedit del que ha fet.

$$
\left[\text { SubjExp(pr-prep) }{ }_{B}\right. \text { ] }
$$

(22) a. L'Enric s'emociona (amb la música). $\rightarrow$ L'Enric \{està / ha quedat $\}$ emocionat (amb la música).

[Subj(i)Exp(pr)]

b. L'Enric s'emmurria (amb aquesta situació). $\rightarrow$ L'Enric \{està / ha quedat $\}$ emmurriat (amb aquesta situació).

[Subj(i)Exp(pr-ci)]

A continuació recullo uns quants exemples de textos literaris amb construccions resultatives de verbs SubjExp(pr-prep) $)_{A}(23)-(26)$ i SubjExp(pr-prep) ${ }_{B}(27)$. Hi deixo constància de més

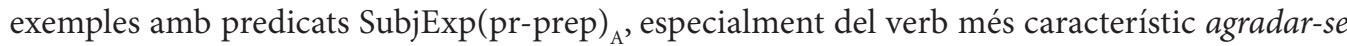
(de) (23), però també de desagradar-se (de) (24) i plaure’s (en) (25), per mostrar que en els dialectes que utilitzen aquests verbs - o en els usos més antics en què s'utilitzaven - és possible la construcció resultativa, com també ho és en l'ús actual i més general del verb interessar-se \{en/ per) $(26){ }^{22}$

(23) a. [...] una noia que estigui agradada d’un, i que en lloc de dir-li “ratolí meu” t'aporrini a crits i no et calli mai [...] la veritat no m’acabava de fer el pes. (Folch i Torres 1920: 18)

b. És a dir, que vós us penseu que encara n’estic agradat, de la Maria Rosa? (Guimerà 1983: 105)

c. Me so agradat de una mossa / Tala com Deu la ha criada. (García 1871: 37)

d. [...] jo’m só agradat de la rosa, / que és lo nom del meu amor. (Verdaguer 1902: 4)

e. Refr. [...] -i) «Cada qual està agradat de les seves coses» (Solsona). (DCVB, entrada cosa)

(24) [...]: cada dia mes desagradat del mon y mes agradat de Deu, per sa infinita misericordia. (Verdaguer 1983: 234)

(25) «Que Sa Majestat fos plaguda d’ordenar un report, per a ésser presentat [...]». [...], perquè la Vostra Majestat vulgui ésser graciosament plaguda de continuar la Vostra Interposició de la manera més urgent. (Soldevila 1929: 213-214)

22 Hi ha un quart contraargument que podria abonar la configuració inacusativa amb un subjecte intern dels verbs SubjExp(pr-prep) i SubjExp(pr-prep) $)_{\mathrm{B}}$ : la possibilitat de fer la substitució pronominal del subjecte experimentador pel clític en, comportament que coincidiria amb el dels verbs ergatius pronominals no inherents o inherents (Sén van \{espantar / emocionar / abstreure / emmurriar\} dues, de persones), tenint en compte que aquestes proves substitutòries s'han de fer amb sintagmes quantificats, atesa la resistència general dels verbs psicològics als sintagmes escarits postverbals (cf. Royo 2017b). Però la majoria de verbs SubjExp(pr-prep) ${ }_{\mathrm{A}}$ i SubjExp(pr-prep) ${ }_{\mathrm{B}}$ regeixen un SPrep introduït per la preposició de, i no és possible la doble substitució pel mateix clític en dels dos elements dislocats i introduïts per la mateixa preposició de ('Se níagraden tres, de nois, de la professora; 'Sén penedeixen dues, de persones, del que han fet). Per això, s'ha de comprovar que és possible la doble substitució pronominal amb verbs que regeixin un SPrep introduït per una preposició diferent de la preposició de. Oracions com Se $\underline{n} \underline{\underline{h}}$ van interessar dues, de persones, per la literatura o Se $\underline{n}$ hi i enfaden moltes, de persones, amb la Maria poden semblar acceptables, però cal ser prudent amb aquesta prova: la dificultat de la doble tematització i la substitució amb dos clítics en contacte fa poc practicable aquest ús i, de fet, no n'he trobat cap exemple. 
(26) [...] si el receptor està interessat en l'oferta, ha de continuar negociant. (Llodrà 2003: 324)

(27) a. [...] i no estic gens penedit de l’esforç realitzat. (Colón 1994: 30)

b. Ell no està enamorat de mi; ni ho crec ni ho vull creure; ell està compadit de mi i es veu que és romàntic, i això l'ha colpit. (Rodoreda 2006: 57)

c. [...], i em tenien tan embegut en allò que veia, que ja no em recordava de llegir ni d'escriure. (Oller 1962: 105)

\section{Proposta d'estructura argumental}

Un cop feta la hipòtesi agentiva amb un subjecte argument extern dels predicats SubjExp(prprep $)_{A}$ i SubjExp(pr-prep $)_{B}$ i vistos els arguments en contra d'aquesta hipòtesi, sembla que ens trobem en un atzucac. Des del punt de vista semàntic, són oracions que expressen un subjecte experimentador amb característiques d'un agent que actua amb voluntarietat $i$, alhora, amb característiques d'un pacient que pot experimentar un estat resultant. Des del punt de vista sintàctic, són oracions compatibles amb una estructura agentiva d'un subjecte experimentador argument extern i, alhora, amb una estructura inacusativa d'un subjecte experimentador argument intern.

Per resoldre aquesta aparent contradicció és útil una observació de Ramchand (2008: 71-89 i nota 6), en què l'autora explica les diferències entre els subjectes d'oracions inacusatives no agentives (The butter melted), d'oracions inacusatives agentives (Michael arrived) i d'oracions inergatives (Alex ran). Segueix el seu marc teòric d'estructura argumental, composta per un initP (sintagma iniciador) que introdueix un initiator o 'subject' of cause en posició d'argument extern, un procP (sintagma procés) que introdueix un undergoer o 'subject' of process com a argument intern i un resP (sintagma resultant) que introdueix un resultee o 'subject' of result en la posició més profunda de l'estructura (cf. Ramchand 2008: 38-42). Crucialment, afirma que hi ha oracions inacusatives agentives, i en parlar d'un verb com arrive diu el següent:

I see no English-internal reason for ascribing a verb like arrive to the class of verbs that has no initiation component. [...] I will analyse a verb like arrive as containing a single DP argument which initiates its own transition to a final locational state - it is simultaneously the initiator, undergoer and resultee. Moreover, because the verb identifies all three heads in this functional decomposition, the resulting predication is punctual (Ramchand 2008: 78-79).

Afirmar que un mateix argument pot ser iniciador (initiator) i alhora tema o pacient (undergoer i resultee) implica, lògicament, renunciar al criteri temàtic de Chomsky (1981) (thetacriterion), segons el qual a cada argument del verb se li associa un paper temàtic i només un, i cada paper temàtic pot ser assignat a un argument i només a un.

Mateu (2015) també afirma que hi ha oracions inacusatives agentives. Ho mostra en una oració amb el verb venir del català antic (28): d’una banda, és una oració conjugada amb l'auxiliar ésser (eren venguts), fet que indica inacusativitat (cf. GIEC \$21.4f); de l’altra, inclou una clàusula de finalitat (a negociar ab mi), la qual cosa expressa agentivitat. 
(28) uns hòmens de Marthorell que eren venguts a negociar ab mi. (1525-1542, Liori i Requesens, Epistolaris, c. 177, 1. 10) (Mateu 2015: 137 (17g), 145)

L'anàlisi de Ramchand (2008) d'un verb de moviment com arribar, amb un argument amb més d'un paper temàtic, no coincideix amb l'anàlisi que en fa Mateu (2015), per a qui arribar pot participar en oracions inacusatives — sense argument extern- quan el subjecte tema és de natura definida o en oracions existencials impersonals - amb un pronom datiu/locatiu argument extern (realitzat o no)— quan el subjecte tema és de natura indefinida. ${ }^{23}$ Per a Ramchand (2008: 78, nota 6), una oració com Michael arrived no és nuclearment inacusativa perquè té un initiator —que és un argument extern-; en canvi, per a Mateu (2015: 146), una oració com El Miquel va arribar - amb un subjecte tema definit- és pròpiament inacusativa perquè no té argument extern.

No entraré a discutir aquest debat sobre els verbs de moviment, tot i que n'aprofitaré alguns conceptes. Em limito a utilitzar l'aportació de Ramchand (2008) i Mateu (2015) sobre l'existència d'oracions inacusatives agentives en l'estudi de l'estructura argumental dels predicats SubjExp(pr-prep) ${ }_{A}$ i SubjExp(pr-prep) dins el marc teòric de Cuervo (2003). Més en concret, assumeixo la possibilitat apuntada per Ramchand (2008) que un mateix argument pugui ser alhora un agent (initiator) en posició d'argument extern i un pacient (undergoer) que pot experimentar un estat o una localització resultant (resultee) en posició d'argument intern. Tenint en compte aquests supòsits, proposo que l'estructura d'oracions amb verbs SubjExp(pr-prep) i SubjExp(pr-prep) $)_{B}$ és una construcció inacusativa en què la posició d'argument extern s'ocupa de manera derivada (per Internal Merge) i el subjecte agafa així un valor agentiu, a més del valor originari de pacient. ${ }^{24}$ La hipòtesi apuntada provisionalment i de manera esquemàtica a (20b) — i discutida posteriorment amb contraarguments - es resoldria amb la nova proposta esquemàtica de (29). ${ }^{25}$

(29) Oracions amb verbs SubjExp(pr-prep) ${ }_{\mathrm{A}}$ i SubjExp(pr-prep)

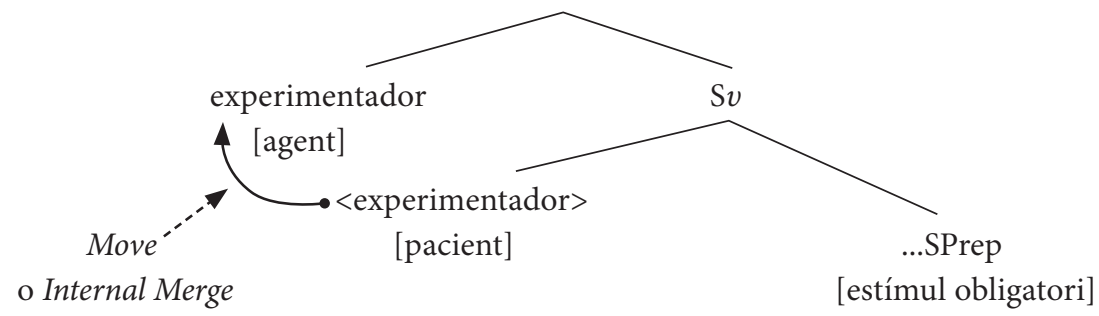

23 Per a una anàlisi diferent de la de Mateu 2015 en l’àmbit català, vegeu Gràcia 1989, Rigau 2013 i GIEC \$21.4.2.

24 Per a una explicació dels conceptes tradicionals de Merge (projection) i Move (checking), reformulats en els postulats minimalistes més recents com a External Merge i Internal Merge (Copy, Merge and Delete), respectivament, vegeu Gelderen 2009: 232-235.

25 Cal tenir en compte que és una proposta estructural que adopto per explicar el comportament d'aquests verbs en un marc teòric concret, però en el model de Ramchand (2008) no es parla de moviment ni d'Internal Merge. 
A (30a) faig la proposta d'estructura argumental dels predicats $\operatorname{SubjExp(pr-prep)_{A}}$ i SubjExp(pr-prep) ${ }_{\mathrm{B}}{ }^{26}$ i a (30b) recullo l'estructura dels verbs ergatius pronominals Subj(i) $\operatorname{Exp}(\mathrm{pr})$ i Subj(i)Exp(pr-ci) per fer-ne una comparació.

(30) a. L'Enric s'interessa per la literatura. L'Enric es penedeix d'haver-ho fet.

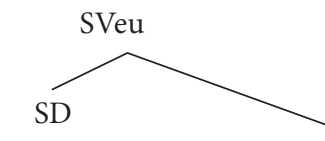

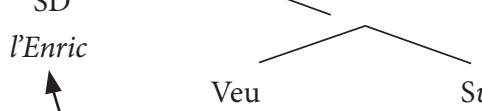
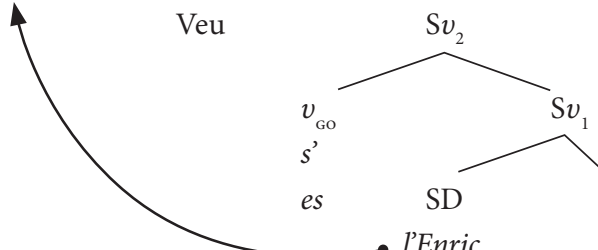

$s^{\prime}$

es

$\mathrm{SD}$

- l'Enric

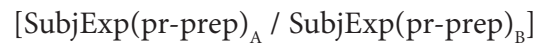

[subjecte agent i pacient alhora: predicat volitiu i emotiu]

b. L'Enric s'espanta.

L'Enric s'emmurria.

A diferència de (30b), lestructura de (30a) no seria nuclearment inacusativa per tenir un initiator, segons Ramchand (2008), ni pròpiament inacusativa per tenir un argument extern, segons Mateu (2015), plantejament que obligaria a crear i definir una nova etiqueta sintàctica estructural on encabir estructures «pseudoinacusatives». En aquest treball presento un plantejament diferent i proposo considerar la inacusativitat com una caracterització general que pot tenir diverses manifestacions específiques, diversos tipus de construccions inacusatives (cf. Cuervo 2010b), una explicació compatible amb la generalització de Burzio (1986). El fenomen estructural comú de totes les construccions inacusatives seria l'absència d'un argument intern acusatiu i l'absència en origen o de forma no derivada d'un argument extern nominatiu, que obliga l'oració a seguir

26 Hi ha autors que consideren que el tret semàntic de voluntarietat o agentivitat no té un reflex directe en l'estructura argumental. Per exemple, Levin i Rappaport Hovav (1995: 162-163) ho exemplifiquen amb els verbs inacusatius italians salite 'pujar' i cadere 'caure', que es conjuguem amb l'auxiliar essere independentment de la seva interpretació agentiva o no; Mateu (2015) proposa una estructura inacusativa agentiva sense cap argument extern que indiqui agentivitat per a oracions de verbs de moviment amb un subjecte tema definit (El meu amic ja ha arribat). Seguint aquest plantejament teòric, no caldria indicar que el subjecte dels verbs SubjExp(pr-prep) i SubjExp(pr-prep) ${ }_{B}$ ocupa de manera derivada la posició d'argument extern (per Internal Merge) per prendre un valor agentiu, a més del valor originari de pacient. És un plantejament que s'adiu amb postulats més restrictius de l'estructura argumental, que defensen l’autonomia de la sintaxi respecte de la semàntica (cf. Hale i Keyser 1993, 2002; Marantz 2013). 
estratègies diverses per presentar un subjecte formal (cf. Rigau 1991, 1999, 2005). ${ }^{27}$ En aquest

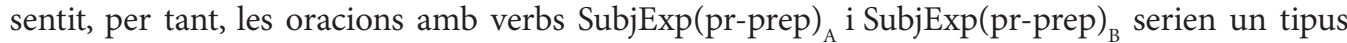
concret doracions inacusatives. Com es pot comprovar a les dues estructures de (30), els verbs SubjExp(pr-prep) i SubjExp(pr-prep) $)_{\mathrm{B}}$ comparteixen una part estructural inacusativa amb els verbs $\operatorname{Subj}(\mathrm{i}) \operatorname{Exp}(\mathrm{pr})$ i Subj(i)Exp(pr-ci), amb un subjecte argument intern en tots dos casos, però - a banda de la inclusió obligatòria o optativa del SPrep, respectivament - es diferencien per la presència d'un subjecte derivat argument extern a (30a) i l'absència d'argument extern a (30b): tindríem, per tant, dos tipus diferents d'oracions inacusatives amb un argument intern amb cas estructural nominatiu. Semànticament, els verbs SubjExp(pr-prep $)_{\mathrm{A}}$ i SubjExp(pr-prep) ${ }_{\mathrm{B}}$ són alhora volitius (subjecte agent) i emotius (subjecte pacient); en canvi, els verbs Subj(i)Exp(pr) i Subj(i) $\operatorname{Exp}(\mathrm{pr}-\mathrm{ci})$ són només emotius (subjecte pacient).

En aquest punt cal fer una remarca sobre la natura semàntica agentiva de l'argument extern derivat de (30a). Si analitzem una altra estructura bieventiva - que permet expressar un canvi d'estat - amb un agent, corresponent a les oracions amb verbs AcExp (31) - seguint la proposta de Cuervo (2003: \$1.3.4) per a les oracions causatives_-, comprovem que la natura verbal de l'event $\mathrm{S} v_{2}$ en posició estructural superior és un $\mathrm{S} v_{\text {Do }}$, que selecciona un subjecte extern no derivat que pot ser tant un agent com un causador no agentiu. Defineixo la natura semàntica de l'argument en aquesta posició com una causa externa activa, i quan es tracta d'un agent l'anomeno un agent extern o agent ${ }_{E}$, diferent de l'experimentador, una causa externa agentiva que provoca o inicia un canvi d'estat en un experimentador. Ara bé, a l'estructura de (30a) la natura verbal de l'event $S v_{2}$ en posició estructural superior és un $\mathrm{S} v_{\mathrm{GO}}$ : és un event dinàmic -com ho mostren les proves de (18)-(19) de l'apartat $\$ 2.1$ - però diferent d’un $S v_{\text {Do. }}$ És un $S v_{\text {GO }}$ que en principi no selecciona cap argument extern, com es pot comprovar a (30b). Largument extern només hi pot aparèixer de forma derivada, com proposo a $(30 a)$, però la natura agentiva d'aquest argument extern ha de ser diferent de la d'un agent, en estar inserit en una estructura diversa: el defineixo com un agent intern o agent, que coincideix amb l'experimentador, una causa interna agentiva que inicia el seu propi procés de canvi d’estat (és alhora un experimentador pacient).

(31) $\{$ L’Arnau / El fum $\}$ va espantar l'Enric.

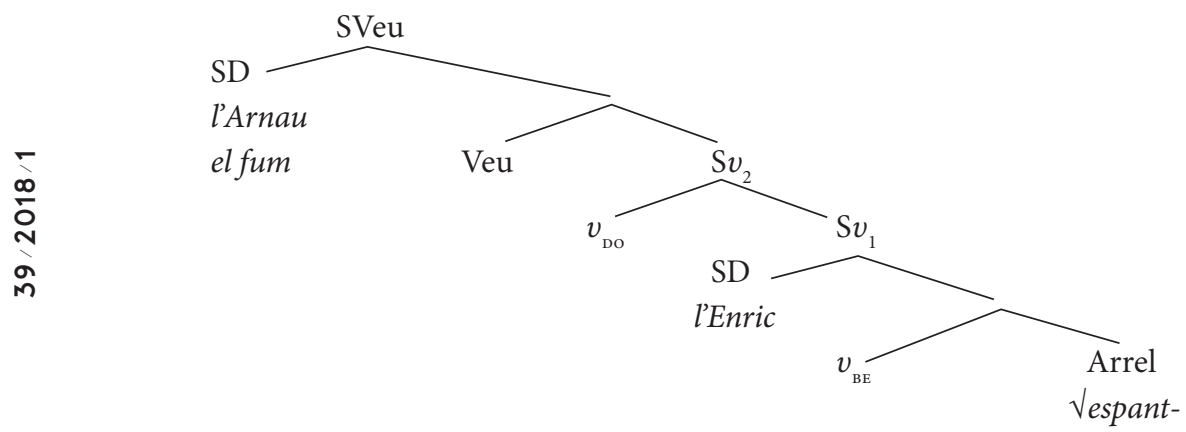

27 L'argument intern pot prendre cas estructural nominatiu per actuar com a subjecte gramatical, com s'esdevé en aquest cas. Però l'oració pot seguir altres estratègies per aconseguir un subjecte formal si l'argument intern presenta cas inherent partitiu. 
En la comparació de les dues estructures de (30) hi trobem unes quantes característiques compartides. L'estructura bieventiva complexa $\mathrm{S} v_{\mathrm{GO}}+\mathrm{S} v_{\mathrm{BE}}$ fa possible inserir-hi un aplicatiu mitjà - cf. Cuervo 2003; Schäfer 2008- i també permet expressar un canvi d'estat o un procés ('esdevenir + participi') (32). ${ }^{28}$ Si tenim en compte només el $\mathrm{S} v_{\mathrm{BE}}$ estatiu en posició estructural inferior, que representa l'estat resultant designat per l'arrel verbal, obtenim les construccions resultatives en tots dos casos ('estar o quedar + participi') (33), com les recollides a (21)-(27). A més, la col-locació del SD l'Enric en posició d'especificador en totes dues estructures impedeix que pugui ser un sintagma nominal escarit postverbal (34) (cf. Cuervo 2003: \$3.1.1.2).

(32) a. 'l'Enric inicia el seu propi procés d'esdevenir interessat per la literatura o d'esdevenir penedit d'haver-ho fet' a (30a)

b. 'l'Enric esdevé espantat o emmurriat' a (30b)

(33) a. 'I'Enric \{està / ha quedat\} interessat per la literatura o penedit del que a fet' a (30a)

b. 'l'Enric \{està / ha quedat $\}$ espantat o emmurriat' a (30b)

(34) a. ${ }^{*}$ ' interessen persones per la literatura; ${ }^{*}$ Es penedeixen persones del que han fet.

b. ${ }^{\star}$ S’espanten persones; ${ }^{\star S}$ 'emmurrien persones.

Finalment, hi ha una diferència a la part inferior de totes dues estructures de (30). El SPrep és obligatori a (30a), com un complement de l'arrel incorporat a l'estructura per una relació de selecció: es pot comprovar la presència obligatòria del SPrep en les diferents paràfrasis de (32a)

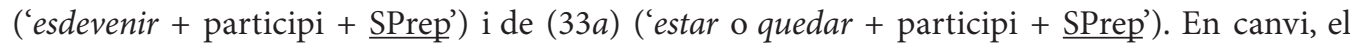
SPrep és optatiu a (30b), un SPrep incorporat a l'estructura per una relació d'adjunció, com un adjunt lèxic (cf. Mateu 2000): L'Enric s'espanta (amb la tempesta); L'Enric s'emmurria (amb el que li has dit). Els verbs SubjExp(pr-prep) $)_{\mathrm{A}}$ i SubjExp(pr-prep) $)_{\mathrm{B}}$-a diferència dels Subj(i)Exp(pr) i Subj(i)Exp(pr-ci) - no poden prescindir de l'estímul de l'experiència psicològica. Però en el cas dels SubjExp(pr-prep) $)_{A}$ és un tret compartit amb els predicats DatExp, dels quals són alternants (cf. Royo 2017a: 76-77), i aquesta inseparabilitat de l'estímul és absoluta, no existeix una accepció ergativa Subj(i)Exp(pr-ci) *interessar-se; en canvi, alguns verbs SubjExp(pr-prep) ${ }_{\mathrm{B}}$ presenten alternants ergatius pronominals (sense un SPrep obligatori), que poden ser no inherents (alegrar-se, avergonyir-se) o inherents (penedir-se). ${ }^{29}$

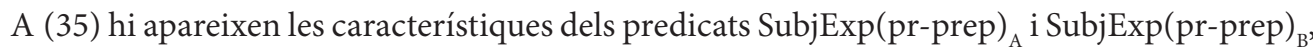
i s'hi indica quins són els trets que comparteixen o no amb els predicats $\operatorname{Subj}(i) \operatorname{Exp}(\mathrm{pr})$ i $\operatorname{Subj}(\mathrm{i})$ $\operatorname{Exp}(\mathrm{pr}-\mathrm{ci})$.

28 Segons la GIEC, els verbs psicològics ergatius pronominals designen «el procés que condueix a un canvi d’estat» (\$21.5b) o «a un canvi d’estat psicològic» $(\$ 21.5 \mathrm{c})$. Per a una anàlisi diferent dels verbs psicològics ergatius de l'espanyol, vegeu Marín - McNally (2011). Hi ha un altre grup de predicats psicològics formalment molt similars

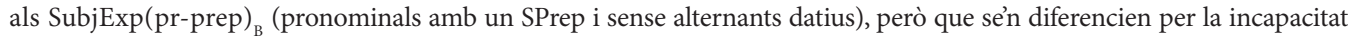
per expressar un experimentador pacient que desenvolupa un canvi d'estat $\mathrm{i}$ arriba a un estat resultant: atrevir-se a, estar-se de, rabejar-se en, animar-se a 'decidir-se amb ànim', molestar-se a 'fer una cosa que causa molèstia', preocupar-se de 'ocupar-se $\mathrm{amb}$ un interès especial. Són verbs que expressen una semàntica oracional volitiva força transparent; els etiqueto com a SubjExp(pr-prep) ${ }_{C}$.

29 Per a l’accepció Subj(i)Exp(pr) de alegrar-se i avergonyir-se, en contrast amb l'accepció SubjExp(pr-prep) ${ }_{B}$, vegeu els exemples de (10)-(12). Per a l'accepció Subj(i)Exp(pr-ci) de penedir-se, vegeu els exemples pronominals de la nota 1. 
(35) L'Enric s'interessa per la literatura. / L'Enric es penedeix d'haver-ho fet.
$\left[\right.$ SubjExp(pr-prep) $\left.{ }_{\mathrm{A}}\right]$
$\left[\right.$ SubjExp(pr-prep) $\left.{ }_{B}\right]$

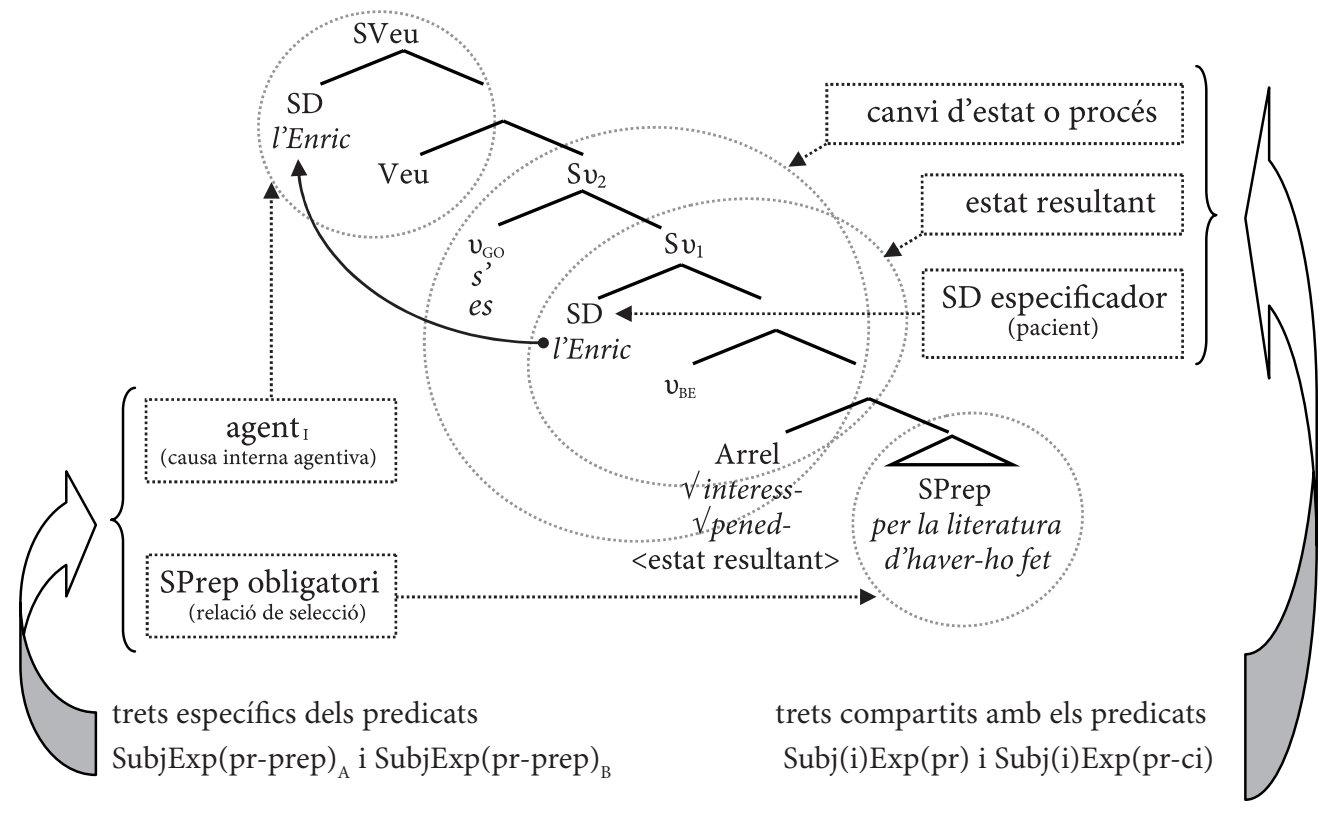

\section{Conclusions}

Alguns verbs psicològics catalans són formes pronominals que regeixen un SPrep i presenten unes característiques oracionals aparentment contraposades: semànticament, expressen un subjecte experimentador amb voluntarietat que alhora és un pacient; sintàcticament, presenten una estructura compatible amb un experimentador subjecte extern i subjecte intern. Poden ser alternants d'estructures diverses amb contingut semàntic emotiu per formar una alternança emotiva/volitiva: per exemple, verbs DatExp (interessar vs. interessar-se $\{$ en/per\}) o verbs ergatius pronominals (avergonyir-se vs. avergonyir-se de).

Defenso que aquests predicats presenten una estructura inacusativa agentiva en què el subjecte experimentador ocupa la posició d'argument intern i alhora d'argument extern derivat per Internal Merge. Consegüentment, l'experimentador és alhora un pacient i un agent, un agent entès com una causa interna activa que inicia el seu propi procés de canvi d'estat.

L'alternança emotiva/volitiva és una mostra més del ric joc d'alternances dels verbs psicològics catalans i una manifestació de la flexibilitat semàntica i sintàctica que els caracteritza. Aquestes alternances indiquen que els elements lèxics s'han d'entendre com a components dinàmics, amb un comportament semàntic i sintàctic derivat de les construccions oracionals en què participen. 


\section{Referències bibliogràfiques}

Abrines, B. (2016). Els verbs de canvi d’estat i l’alternança causativa en català. Tesi doctoral. Universitat Autònoma de Barcelona.

Acedo-Matellán, V.; \& Mateu, J. (2015). Los verbos psicológicos: raíces especiales en estructuras corrientes. In R. Marín (Ed.), Los predicados psicológicos (pp. 81-109). Madrid: Visor Libros.

[DCVB]: Alcover, A. M.; \& Moll, F. (1862-1932). Diccionari català-valencià-balear (10 vol.). Palma. Editorial Moll. $<$ http://dcvb.iecat.net/>

Alexiadou, A. (2014). Roots don't take complements. Theoretical Linguistics, 40(3/4), 287-297.

Alexiadou, A.; Anagnostopoulou, E.; \& Schäfer, F. (2006). The properties of anticausatives crosslinguistically. In M. Frascarelli (Ed.), Phases of Interpretation (pp. 187-211). Berlin-New York: Mouton de Gruyter.

Anagnostopoulou, E. (2003). The Syntax of Ditransitives. Evidence from Clitics. Berlin-New York: Mouton de Gruyter.

Arad, M. (1998). VP Structure and the Syntax-Lexicon Interface. Cambridge, Mass.: MIT Occasional Papers in Linguistics, 16.

Armstrong, G. (2016). Towards a theory of pronominal verb constructions in Spanish. In A. Cuza, L. Czerwionka \& D. Olson (Eds.), Inquiries in Hispanic Linguistics: From theory to empirical evidence (pp. 21-38). Amsterdam/Philadelphia: John Benjamins.

Baker, M. C. (1988). Incorporation: A Theory of Grammatical Function Changing. Chicago: University of Chicago Press.

Batllori, M. (2012). Diacronía de los verbos psicológicos: una propuesta de entrada léxica. In G. Clavería, M. Freixas, M. Prat \& J. Torruella (Eds.), Historia del léxico: perspectivas de investigación (pp. 341-374). Madrid-Frankfurt am Main: Iberoamericana-Vervuert.

Belletti, A.; \& Rizzi, L. (1988). Psych-Verbs and Theta-Theory. Natural Language and Linguistic Theory, 6 (3), 291-352.

Burzio, L. (1986). Italian Syntax: A Government-Binding Approach. Dordrecht: Springer.

Cabré, T.; \& Mateu, J. (1998). Estructura gramatical i normativa lingüística: a propòsit dels verbs psicològics en català. Quaderns. Revista de traducció, 2, 65-81.

Chomsky, N. (1981). Lectures on Government and Binding. Dordrecht: Foris.

Cuervo, M. C. (2003). Datives at Large. PhD dissertation. Massachusetts Institute of Technology.

. (2010a). La estructura de expresiones con verbos livianos y experimentante. In M. Luján \& M. Groppi (Eds.), Cuestiones gramaticales del español, últimos avances. Cuadernos de la Alfal, Nueva Serie, 1, 2010 (pp. 194-206). Santiago de Chile: Asociación de Lingüística y Filología de la América Latina (ALFAL).

_ (2010b). Some Dative Subjects Are Born, Some Are Made. In C. Borgonovo, M. Español-Echevarría \& P. Prévost, Selected Proceedings of the 12th Hispanic Linguistics Symposium (pp. 26-37). Somerville, MA: Cascadilla Proceedings Project.

(2014). Arguments for a root. Theoretical Linguistics, 40(3/4), 375-387.

Demonte, V. (1989). Teoría sintáctica: de las estructuras a la rección. Madrid: Síntesis.

Elizaincín, A.; \& González, M. (2016). El cambio lingüístico gusto de X $\rightarrow$ me gusta X. Lingüística y Literatura, 69, 253-268.

Folli, R.; \& Harley, H. (2005). Flavors of v. In P. Kempchimsky \& R. Slabakova (Eds.), Aspectual Inquiries (pp. 95-120). Dordrecht: Springer.

Gallego, A. J. (2010). El complemento de régimen verbal. Lingüística Española Actual, XXXII/2, 223-258. 
Gavarró, A.; \& Laca, B. (2008). Les perífrasis temporals, aspectuals i modals. In J. Solà et al. (Dir.), Gramàtica del català contemporani (3 vol.) (pp. 2663-2726). 4th ed. Barcelona: Editorial Empúries.

Gelderen, E. (2009). Grammaticalization from a biolinguistic perspective. In R. Botha \& C. Knight (Eds.), The Prehistory of Language (pp. 225-243). Oxford-New York: Oxford University Press.

[DUVC]: Ginebra, Jordi; \& Montserrat, Anna (2009). Diccionari d'ús dels verbs catalans. Règim verbal i canvi i caiguda de preposicions, 2nd ed. [1999: 1st ed. publicada per Edicions 62]. Barcelona: Educaula.

Ginebra, J.; \& Montserrat, A. (2002). Sobre el règim del verb 'interessar'. Llengua i Ús, 25, 44-48.

Gràcia, L. (1989). Els verbs ergatius en català. Ciutadella de Menorca: Institut Menorquí d’Estudis.

Hale, K.; \& Keyser, S. J. (1993). On argument structure and the lexical expression of syntactic relations. In K. Hale \& S. J. Keyser (Eds.), The View from Building 20. Essays in Linguistics in Honor of Sylvain Bromberger (53-109). Cambridge, Mass.: MIT Press.

- (2002). Prolegomenon to a Theory of Argument Structure. Cambridge, Mass.: MIT Press.

Harley, H. (1995). Subjects, events and licensing. PhD dissertation. Massachusetts Institute of Technology.

- (2014). On the identity of roots. Theoretical Linguistics, 40(3/4), 225-276.

Hengeveld, K.; \& Mackenzie, J. L. (2008). Functional Discourse Grammar. New York: Oxford University Press.

Hopper, P, J.; \& Thompson, S. A. (1980). Transitivity in Grammar and Discourse. Language, 56(2), 251299.

[DIEC2]: Institut d'Estudis Catalans (2007). Diccionari de la llengua catalana, 2nd ed. Barcelona: Institut d'Estudis Catalans; Enciclopèdia Catalana; Edicions 62. <http://dlc.iec.cat/>

[GIEC]: - (2016). Gramàtica de la llengua catalana. Barcelona: Institut d'Estudis Catalans.

Jané, A. (1979). Plaure’s en una cosa. Avui, February 11, 1979.

Kratzer, A. (1996). Severing the external argument from its verb. In J. Rooryck \& L. Zaring (Eds.), Phrase Structure and the Lexicon (109-138). Dordrecht: Kluwer.

Laca, B. (1986). Notes per a un estudi del pleonasme pronominal en català. In J. Massot i Muntaner (Ed.), Miscel-lània Antoni M. Badia i Margarit (vol. 5) (pp. 65-88). Barcelona: Publicacions de l'Abadia de Montserrat.

Levin, B. (1999). Objecthood: An event structure perspective. CLS 35, volume 1: The Main Session, 223-247.

Levin, B.; \& Rappaport Hovav, M. (1995). Unaccusativity. At the syntax-lexical semantics interface. Cambridge, Mass.: MIT Press.

[GD62]: López del Castillo, L. (2000). Gran diccionari 62 de la llengua catalana. Barcelona: Edicions 62.

Maldonado, R. (2008). Spanish middle syntax: A usage-based proposal for grammar teaching. In S. De Knop \& T, De Rycker (Eds.), Cognitive Approaches to Pedagogical Grammar (pp. 155-196). Berlin-New York: Mounton de Gruyter.

Marantz, A. (1993). Implications of Asymmetries in Double Object Constructions. In S. A. Mchombo (Ed.), Theoretical aspects of Bantu Grammar (vol 1) (pp. 113-150). Stanford: CSLI Publications.

. (1997). No Escape From Syntax: Don't Try Morphological Analysis in the Privacy of Your Own Lexicon. In A. Dimitriadis, L. Siegel, C. Surek-Clark \& A. Williams (Eds.), PWPL 4.2, Proceedings of the $21^{\text {st }}$ Annual Penn Linguistics Colloquium (pp. 201-225). Pennsylvania: University of Pennsylvania Working Papers in Linguistics.

- (2013). Verbal argument structure: Events and participants. Lingua, 130, 152-168.

Marín, R.; \& McNally, L. (2011). Inchoativity, change of state and telicity. Natural Language and Linguistic Theory, 29, 467-502. 
Marín, R. (2015). Los predicados psicológicos. Debate sobre el estado de la cuestión. In R. Marín (Ed.), Los predicados psicológicos (pp. 11-50). Madrid: Visor Libros.

Masullo, P. J. (1992). Antipassive constructions in Spanish. In P. Hirschbühler \& K. Koerner (Eds.), Romance Languages and Modern Linguistic Theory (pp. 175-194). Amsterdam; Philadelphia: John Benjamins.

- (1999). La interfaz Léxico-Sintaxis: presencia y ausencia del clítico se en construcciones inacusativas. Ms. Universidad Nacional del Comahue. University of Washington.

Mateu, J. (2000). La semàntica relacional de l’estructura argumental i la seva aplicació a una alternança lexicosemàntica del català. Llengua \& Literatura, 11, 281-309.

- (2015). La inacusativitat i la selecció de l'auxiliar en català antic. In M. R. Lloret, C. Pons-Moll \& E. Bosch-Roure (Eds.), Clàssics d’ahir i d’avui en la gramàtica del català (pp. 127-151). Barcelona: Publicacions i Edicions de la Universitat de Barcelona.

Pesetsky, D. (1995). Zero Syntax. Experiencers and Cascades. Cambridge, Mass.: MIT Press.

Picallo, M. C. (1990). Modal Verbs in Catalan. Natural Language and Linguistic Theory, 8(2), 285-312.

Pylkkänen, L. (2008). Introducing arguments. Cambridge, Mass.: MIT Press.

Quer, J. (2008). Subordinació i mode. In J. Solà et al. (Dirs.), Gramàtica del català contemporani (3 vol.) (pp. 2799-2866). 4th ed. Barcelona: Editorial Empúries.

Ramchand, G. C. (2008). Verb Meaning and the Lexicon. A First-Phase Syntax. Cambridge: Cambridge University Press.

Rigau, G. (1990). Les propietats d'agradar: estructura temàtica i comportament sintàctic. Caplletra, 8, 7-19.

- (1991). On the Functional Properties of AGR. Catalan Working Papers in Linguistics, 1, 235-260. (1994). Les propietats dels verbs pronominals. Els Marges, 50, 29-39.

(1999). Los predicados impersonales relativos en las lenguas románicas. Revista Española de Lingüística, 29(2), 317-355.

- (2005). Number Agreement Variation in Catalan Dialects. In G. Cinque \& R. Kayne (Eds.), The Oxford Handbook of Comparative Syntax (pp. 775-805). New York: Oxford University Press.

- (2013). La preposició silent d'alguns verbs de moviment local. Els Marges, 100, 125-132.

Rosselló, J. (2008). El SV, I: Verbs i arguments verbals. In J. Solà et al. (Dirs.), Gramàtica del català contemporani (3 vol.) (pp. 1853-1949). 4th ed. Barcelona: Editorial Empúries.

Royo, C. (2017a). Verbs psicològics catalans: el cas de agradar i interessar. Caplletra, 62, 65-88.

. (2017b). Alternança acusatiu/datiu i flexibilitat semàntica i sintàctica dels verbs psicològics catalans.

Tesi doctoral. Universitat de Barcelona.

Schäfer, F. (2008). The Syntax of (Anti-)Causatives. Amsterdam; Filadèlfia: John Benjamins Publishing Company.

Todolí, J. (1998). Els pronoms personals. València: Universitat de València.

. (2008). Els pronoms. In J. Solà et al. (Dirs.), Gramàtica del català contemporani (3 vol.) (pp. 1337-1433). 4th ed. Barcelona: Editorial Empúries.

Tsunoda, T. (1985). Remarks on transitivity. Journal of Linguistics, 21, 385-396. 


\section{Textos utilitzats als exemples}

Blanco, E. (2015). La mainadera d'Eugène Bourmont. Valls: Cossetània.

Colón, G. (1994). Els meus mestres. Actes de les Jornades sobre normes i normalització lingüística. Castelló de la Plana, 17-19 desembre de 1992, 60è aniversari de les Normes de Castelló (pp. 27-36). Castelló de la Plana: Publicacions de la Universitat Jaume I.

Folch i Torres, J. M. (1920). La ventafocs. Barcelona: Salvador Bonavía.

García, V. (1871). Poesías jocosas [1700]. Barcelona: Llibreteria Espanyola de I. López Bernagosi, editor.

Guimerà, A. (1983). Maria Rosa. Barcelona: Edicions 62.

Heinemann, K. (2001). Els valors de l'esport. Una perspectiva sociològica (translation into Catalan: M. Corra, K. Heinemann \& N. Puig). Apunts. Educació física i esports, 64, 17-25.

La Bíblia. Versió dels textos originals i notes pels monjos de Montserrat. <http://www.cervantesvirtual. com/obra-visor/la-biblia--0/html/>

Liberal, A. (2012). Recull de metamorfosis (translation into Catalan: J. Almirall Sardà). Barcelona: Fundació Bernat Metge.

Llodrà, F. (2003). Reflexions sobre els PECL i la fase negociadora del contacte. In Àrea de Dret Civil, Universitat de Girona (Coord.), El Dret civil català en el context europeu. Materials de les Dotzenes Jornades de Dret Català a Tossa, 26 i 27 de setembre de 2002 (pp. 321-348). Girona: Documenta Universitaria.

Medina, J. (1987). Carles Riba i Friedrich Hölderlin. Barcelona: Publicacions de l'abadia de Montserrat.

Oller, N. (1962). Memòries literàries. Història dels meus llibres. Barcelona: Editorial Aedos.

Rodoreda, M. (2006). Primeres novel.les. Volum I. Sóc una dona honrada? Del que hom no pot fugir. Barcelona: Fundació Mercè Rodoreda, FP.

Rodríguez, K. L. (2015). Mi Vecino Misterioso. ¿Qué sucede cuando el pasado nos arrastra? California: Windmills International Editions Inc.

Rostand, E. (1985). Cyrano de Bergerac [1897] (translation into Catalan and prologue: X. Bru de Sala). Barcelona: Xavier Bru de Sala.

Soldevila, F. (1929). Unes sessions de la Cambra dels Lords en 1714. Revista de Catalunya, vol. XII, VI, n. $58,210-215$.

Torralba, F. (2012). El valor de tenir valors. Badalona: Ara Llibres.

Verdaguer, J. (1902). Corrandes. In A. Busquets y Punset \& Ll. Carles Viada y Lluch (Eds.), La Mellor Corona. Poesies (pp. 3-4). Barcelona: Tipografia «L'Avenç». . (1983). Epistolari de Jacint Verdaguer (vol. VII, 1889-1891). Barcelona: Editorial Barcino. 


\section{Annex: llista d'etiquetes per als diferents grups verbals}

AcExp

$\operatorname{DatExp}$

SubjExp

$\operatorname{SubjExp}(p r-p r e p)_{A}$

$\operatorname{SubjExp(pr-prep)_{B}}$

$\operatorname{SubjExp}(\text { pr-prep })_{C}$

$\operatorname{Subj}(i) \operatorname{Exp}(p r)$

$\operatorname{Subj}(i) \operatorname{Exp}(p r-c i)$ verb psicològic amb experimentador acusatiu, com espantar (cf. tipus II de Belletti i Rizzi 1988)

verb psicològic amb experimentador datiu, com agradar (cf. tipus III de Belletti i Rizzi 1988)

verb psicològic amb subjecte experimentador, com estimar (cf. tipus I de Belletti i Rizzi 1988)

verb psicològic pronominal amb subjecte experimentador i règim preposicional que pot expressar un estat resultant i que té un alternant DatExp, con interessar-se $\{$ en $/ p e r\}$

verb psicològic pronominal amb subjecte experimentador i règim preposicional que pot expressar un estat resultant i que no té un alternant DatExp, com penedirse de

verb psicològic pronominal amb subjecte experimentador i règim preposicional que no pot expressar un estat resultant i que no té un alternant DatExp, com atrevir-se a

verb psicològic ergatiu pronominal amb subjecte intern experimentador i alternant AcExp, com emocionar-se

verb psicològic ergatiu pronominal amb subjecte intern experimentador i sense alternant AcExp (verb psicològic ergatiu pronominal inherent), com emmurriar-se 